\title{
A insurgência de uma geração de jovens conservadores: reflexões a partir de Karl Mannheim
}

\author{
WIVIAN WELLER ${ }^{I}$
}

e LUCÉLIA DE MORAES BRAGA BASSALO II

\section{Introdução}

A CADA nova geração, formas de interpretar e dar sentido à realidade são evocadas pelos jovens em um movimento permanente de construção de novas sociabilidades e de formação identitária. Grupos juvenis assumem características peculiares em um determinado tempo histórico e social, tornando-se representativos de um modo de compreensão e de comunicação de posicionamentos diante de demandas da sociedade. Considerando as continuidades e rupturas entre uma geração e outra, um aspecto se tornou relevante na última década: a emergência de unidades geracionais formadas por jovens conservadores.

Os estudos de Karl Mannheim oferecem um entendimento teórico e uma possibilidade analítica de compreensão dos grupos jovens que se identificam com o conservadorismo na atualidade. Karl Mannheim iniciou sua carreira docente na Universidade de Budapeste, após a defesa da tese de doutorado Análise estrutural da epistemologia defendida em 1918. Em 1920 foi obrigado a exilar-se do país, estabelecendo-se na cidade de Heidelberg na Alemanha durante os anos 1920. Produziu intensamente durante esse período, consagrando-se como um dos mais importantes fundadores da Sociologia do Conhecimento, especialmente a partir da publicação do livro Ideologia e Utopia em 1929 (Knoblauch, 2005). Seu estudo sobre o conservadorismo foi apresentado como tese de livre-docência na Universidade de Heidelberg em 1925 com o título Altkonservatismus: ein Beitrag zur Soziologie des Wissens [Velho conservadorismo: uma contribuição para a sociologia do conbecimento] e foi avaliada por Emil Lederer, Alfred Weber e Carl Brinkmann. Essa tese concedeu a Mannheim o título de Privatdozent e possibilitou a retomada de sua carreira docente. Passaram-se quase 60 anos até a publicação da versão integral da tese (1984 em língua alemã e 1986 em inglês), resultado de um esforço dos pesquisadores David Kettler, Volker Meja e Nico Stehr, que se debruçaram sobre o manuscrito original encontrado 
entre os documentos de Paul Kecskemeti que falecera em 1980. ${ }^{1}$ Nesse sentido, por muito tempo os leitores tiveram acesso apenas ao artigo "O pensamento conservador", publicado pela primeira vez em 1927 na revista Archiv für Sozialwissenschaft und Sozialpolitik e em inglês na coletânea Essays on Sociology and Social Psychology no ano de $1953^{2}$ e às análises sobre o conservadorismo burocrático e o historicismo conservador na obra Ideologia e Utopia, publicada em 1929.

Seus escritos representam um estudo histórico-sociológico de estilos de pensamento situados na primeira metade do século XIX na Alemanha. Nesse período, segundo Mannheim (1984, p.47), desenvolveu-se em algumas camadas sociais "um pensamento com uma marca peculiar e uma imputabilidade sociológica claramente aferível" que pode ser definido como conservadorismo. Além de situar o problema, a análise do estilo de pensamento conservador contempla não só elementos gerais, como a natureza e o conceito de conservadorismo, mas também o desenvolvimento histórico de algumas correntes conservadoras, tratadas especialmente na terceira parte de sua tese de livre docência (ibidem, p.137-224). Seu trabalho não se restringe ao estudo do conservadorismo, mas é também uma análise do estilo de pensamento conservador em oposição ao estilo de pensamento liberal, que contribui para o entendimento dos grupos de jovens conservadores na contemporaneidade.

\section{Estilo de pensamento conservador e transmissão geracional}

Ao adotar o conceito de "estilo de pensamento" ao invés de "hábito de pensamento", utilizado à época pela sociologia anglo-saxã, Mannheim destaca que se o pensamento se desenvolvesse apenas a partir do processo de formação de hábitos, teríamos a perpetuação de um mesmo padrão e dificilmente ocorreriam mudanças e o surgimento de novos hábitos. A própria história tem demonstrado que o pensamento humano muda constantemente, sobretudo nas sociedades dinâmicas. Recorrendo ao conceito de estilo da história da arte, Mannheim (1971, p.133) sustenta que o "pensamento humano também se desenvolve em 'estilos' e que existem diferentes escolas de pensamento que se distinguem pelas diferentes formas com que usam diferentes padrões ou categorias de pensamento".

Em relação ao surgimento do estilo de pensamento conservador como uma corrente independente, Mannheim destaca que isso ocorreu quando determinados grupos se viram obrigados a assumir uma posição consciente diante do pensamento revolucionário burguês e ao modo de pensar do direito natural:

O conservadorismo se torna consciente e reflexivo pela primeira vez quando outros modos de vida e pensamento aparecem em cena, contra os quais se vê obrigado a pegar em armas na luta ideológica. Esta é a primeira etapa na formação de uma ideologia definitivamente conservadora; é também uma etapa de deliberação metodológica na qual o conservadorismo tenta se tornar consciente de sua essência. (Mannheim, 1971, p.173) 
As denominações liberal e conservador na primeira metade do século XIX não remetem apenas a afinidades políticas. São visões de mundo absolutamente diferentes, que ganharam forma em um determinado espaço vital (Lebensraum) e em uma determinada constelação, ${ }^{3}$ adquirindo um caráter dinâmico e de adaptação a outros núcleos sociais e situações (Mannheim, 1984; Barbosa, 2005). Apesar de assumir elementos tradicionalistas, o estilo de pensamento conservador moderno não pode ser confundido com o conservadorismo natural, melhor definido como tradicionalismo, que não possui traços históricos e se configura como uma conduta instintiva ou reativa em relação a reformas deliberadas e uma "daquelas tendências adormecidas que cada indivíduo inconscientemente abriga dentro de si" (Mannheim, 1971, p.157). Na esfera individual ele não gera $a$ priori um conflito: "não há necessariamente uma contradição no fato de que uma pessoa politicamente progressista reaja de uma forma inteiramente tradicionalista em seu cotidiano" (ibidem, p.156). Em oposição ao tradicionalismo, o conservadorismo moderno, segundo o autor, é uma entidade com uma continuidade histórica e social que se constituiu, desde o princípio, de modo consciente e reflexivo, ou seja, como um "contramovimento em oposição consciente ao movimento 'progressista' altamente organizado, coerente e sistemático" (ibidem, p.157). Trata-se, portanto, de um movimento intencional e, sobretudo, proposital em relação às circunstâncias, que mudam de uma época para outra.

O que faz surgir um movimento conservador e de que forma ele opera? Para Mannheim o mundo social e intelectual moderno produziu uma estrutura própria e particular, possibilitando o surgimento e interação desses movimentos ou tendências nessa mesma estrutura. $\mathrm{O}$ agir conservador depende sempre de um conjunto concreto de circunstâncias e a forma ou dimensão de uma ação conservadora de cunho político não tem como ser antecipada (Mannheim, 1971; 1984). Só é possível determinar de modo aproximado a ação ou comportamento de um conservador ou de alguém que age de acordo com o conservadorismo político de uma determinada época se tivermos "conhecimento da natureza e da estrutura do 'movimento conservador' no país e no período em questão" (Mannheim, 1984, p.94, grifos no original). No entanto, está claro que o agir conservador não é simplesmente uma reação automática, mas pressupõe um tipo de condução, ao menos no sentido político. Nas palavras de Mannheim, a ação conservadora pressupõe "uma orientação consciente ou inconsciente a um modo de pensar e agir, que em seu conteúdo e forma, é sempre historicamente caracterizado e identificado [...] antes mesmo de chegar ao indivíduo" (ibidem, p.94).

Se o agir conservador depende de uma condução consciente ou inconsciente do modo de pensar que, por sua vez, remonta à estrutura social na qual os indivíduos se encontram inseridos, não há como negar a herança cultural e sua reinterpretação pelas novas gerações. A herança cultural dá continuidade ao estilo de pensamento conservador originado no século XIX, mas com novas 
apropriações a cada nova geração e em cada contexto social e político ou em cada constelação, se quisermos utilizar um conceito adotado por Mannheim. A forma como se dá a constante renovação de um estilo de pensamento é desenvolvida com maior profundidade pelo autor em seus estudos sobre o problema das gerações, por exemplo, quando são apontados aspectos que caracterizam os processos interativos e dinâmicos das mudanças geracionais, dentre outros: a constante irrupção de novos portadores de cultura, a saída constante dos antigos portadores de cultura, a limitação temporal da participação de uma conexão geracional no processo histórico, a necessidade de transmissão constante dos bens culturais acumulados e o caráter contínuo das mudanças geracionais (Mannheim, 1993; Weller, 2010).

Em certa medida, o artigo "O problema das gerações", publicado em 1928 na Kölner Vierteljahrhefte für Soziologie, representa uma continuidade das reflexões iniciadas em sua pesquisa anterior sobre o estilo do pensamento conservador em oposição ao estilo de pensamento liberal, mas desenvolvido aqui de forma mais aprofundada, concebendo esses dois estilos de pensamento como pertencentes a "unidades geracionais" distintas que polarizam e entram em disputas, mas que, ainda assim, fazem parte de uma mesma "conexão geracional" (Mannheim, 1964 e 1993), de um mesmo "espaço de experiências conjuntivas", como definido por Mannheim em outros escritos (Mannheim, 1982). Em certa medida, o estudo anterior sobre os estilos de pensamento serviu de base para o refinamento do conceito de gerações e do entendimento de gerações como "espaços de experiência societária" (Bohnsack, 2017, p.216).

A fim de melhor compreender a especificidade de uma unidade geracional enquanto herdeira e defensora de um estilo de pensamento conservador moderno que busca construir seu espaço de legitimação por meio da herança cultural e da polarização com outros estilos de pensamento, é necessário compreender a diferenciação e a relação existente entre "posição", "conexão" e "unidade" geracional, para, nas palavras de Mannheim (1964, p.553), não incorrer no risco de "misturar os fenômenos biológicos-vitais com os fenômenos correspondentes que formam as forças socioespirituais".

A posição geracional (Generationslagerung ${ }^{5}$ ), em um sentido mais objetivista, é dada ou fundamentada pelo "ritmo biológico da existência humana: através dos fatos da vida e da morte, através do fato do tempo de vida reduzido e através do fato do envelhecimento" (ibidem, p.527). Esse pertencimento a uma geração dado pelo ano de nascimento faz que as pessoas se encontrem em posições parecidas na corrente histórica dos acontecimentos sociais. Contudo, a posição não pode ser deduzida imediatamente das estruturas biológicas: "Estar fundamentado em algo não significa ser deduzido, estar contido nesse algo" (ibidem). A posição, em si mesma, "só detém possibilidades potenciais, que podem ser realçadas, reprimidas ou surgir com um efeito modificado, quando sedimentadas em outras forças sociais influentes (ibidem, p.542). Nesse sentido, 
Schäffer (2003) destaca que decisivo para a posição geracional, tal como posto por Mannheim, é a potencialidade ou possibilidade de as pessoas poderem compartilhar estratos de experiência de natureza semelhante ou similares a estas e não apenas a sua facticidade, o seu fundamento biológico.

A conexão geracional (Generationszusammenhang), por sua vez, é mais determinante e pressupõe um vínculo concreto, uma participação em uma prática coletiva. Mannheim recorre a Heidegger e define esse vínculo como uma participação no destino coletivo de uma situação histórico-social: "Enquanto a posição social é somente algo potencial, a conexão geracional se constitui através da participação dos indivíduos que pertencem à mesma posição geracional, em um destino coletivo comum assim como da partilha de conteúdos que estão relacionados de alguma forma" (ibidem, p.547).

No contexto de um destino coletivo e de sua dinâmica social, podem surgir unidades geracionais (Generationseinheiten), que representam um vínculo ainda mais concreto em relação àquele estabelecido pela conexão geracional, relacionado às vivências e ao modo como, por exemplo, a juventude opera com uma mesma problemática histórica e atual: "aqueles grupos que dentro da mesma conexão geracional operam com essas vivências de modo distinto, constituem, em cada caso, distintas 'unidades geracionais' no âmbito de uma mesma conexão geracional" (ibidem, p.544). Em outras palavras, a forma como grupos processam fatos históricos do seu tempo, a adoção ou criação de estilos de vida diferenciados, mesmo entre aqueles que vivem em um mesmo meio social, provoca o surgimento de distintas unidades geracionais no âmbito de uma mesma conexão geracional.

Como ilustração para a coexistência de distintas unidades geracionais dentro de uma mesma conexão geracional, Mannheim retoma sua análise sobre os estilos de pensamento: "A partir de 1800 é [...] ainda mais clara a evidência de um grupo romântico, que com o passar do tempo se torna cada vez mais conservador, se opondo a uma juventude que se tornava racionalista-liberal" (ibidem, p.543). O conservadorismo romântico e o racionalismo liberal eram dois polos ou modos de operação opostos para lidar com os mesmos acontecimentos históricos, formando, dessa forma, distintas unidades geracionais. Segundo o autor, o primeiro aspecto que chama a atenção quando analisamos a intensidade da interação entre aqueles que pertencem a uma mesma unidade geracional é o elo existente entre os conteúdos que ocupam suas consciências. Por exemplo, a noção de "liberdade era importante para a unidade geracional liberal, não só pelas demandas implicadas em seu conteúdo, mas porque nesses e através desses conteúdos os indivíduos dispersos espacialmente ou de outra forma podiam ser conectados em uma unidade" (ibidem, p.544). No entanto, mais do que o conteúdo em si, o que conecta esses indivíduos são as forças empreendidas na configuração e direcionamento desses conteúdos: "O profundo significado "emocional" de uma palavra-chave, de um gesto autêntico, de uma obra de arte, consiste 
no fato de que com elas conectamos não somente conteúdos, mas também as tendências formativas inerentes e os vínculos coletivos das intenções básicas, que, por meio delas, se conectam com as vontades coletivas" (ibidem, p.545).

Mannheim destaca ainda que não podemos partir do pressuposto que nas primeiras décadas do século XIX existia somente uma geração romântico-conservadora que foi substituída na década de 1930 por uma geração que voltou a ser racional-liberal. No entanto, o autor destaca que somente essa juventude ancorada no pensamento romântico-conservador foi capaz de trazer durante esse período novos significados de vida e de mundo ou novas "enteléquias ${ }^{6}$ geracionais", relacionadas ao espírito do tempo (Zeitgeist) ou a sua desconstrução (Weller, 2010; Schäffer, 2003). É preciso reconhecer que as polaridades básicas sempre existiram e em todas as correntes sempre existiu uma juventude. No entanto, "a possibilidade de formação criativa dos impulsos geracionais, surgiu uma vez no polo romântico-conservador, em seguida no racional-liberal" (Mannheim, 1964, p.559).

Outro aspecto importante da teoria mannheiminiana para a compreensão das unidades geracionais e seus estilos de pensamento diz respeito à "não contemporaneidade dos contemporâneos", ou seja, ao fato de que um grupo geracional convive não só com pessoas da mesma idade que partilham das mesmas experiências em um mesmo meio social, mas também com aqueles que partilham de experiências e visões de mundo distintas. Esses mesmos grupos também convivem com pessoas de idades distintas, proporcionando uma "plenitude de possibilidades contemporâneas" (ibidem, p.517). Consequentemente, Mannheim critica teorias geracionais que tendem a associar os jovens como progressistas e os mais velhos como conservadores, destacando que qualquer relação direta entre estilos de pensamento e dados biológicos "conduz a um quid pro quo, o que só gera confusão" (ibidem, p.535). O que se pode afirmar é que o seu "ser jovem" se manifesta pelo fato de que os jovens realizam "uma transformação e adaptação destas [correntes] à nova situação total com maior facilidade" (ibidem, p.535), o que, do ponto de vista da história e da política, pode ser visto tanto como um avanço na constituição de novos estilos de pensamento, como um recuo ou até mesmo um retrocesso em relação ao que foi construído pelas gerações anteriores.

Quando nos debruçamos sobre a organização de grupos em ambientes virtuais formados por jovens que se definem como conservadores, o engajamento em um "contramovimento" parece ter se configurado como um elemento comum e constituidor dessa unidade geracional, conforme discutiremos a seguir.

\section{A insurgência de uma geração de jovens conservadores}

Tendo em vista a constituição de unidades geracionais que se formam em uma mesma conexão geracional, buscamos identificar grupos de jovens que anunciam publicamente, uma herança cultural relacionada a um estilo de pensamento conservador, no intuito de verificar como ocorre essa transmissão e 
apropriação pelas novas gerações. Nesse sentido, a palavra conservador, compreendida como "estilo de pensamento", orientou a busca em ambientes virtuais, por grupos que se autodenominassem como jovens e conservadores.

A assunção como jovens que se identificam com unidades geracionais conservadoras que lhes antecederam demarca a partilha de uma visão de mundo que se tornou mais visível no Brasil a partir de 2013. É nesse período que eclodem as manifestações de rua que, por meio das redes sociais, ascenderam como grandes eventos de massa a partir de uma insatisfação generalizada com a forma de gestão do país e a "desconfiança em relação aos canais institucionais de participação, bem como desconfiança em relação a associações como partidos ou sindicatos e preferências por ações políticas pouco institucionalizadas" (Corrochano et al., 2018 , p.51). Foi nesse período, e a partir desses eventos, que "surgiu a ideia de reunir a militância liberal em um movimento mais amplo, que não se restringisse às limitações existentes pelas organizações criadas até então" (Rocha, 2019, p.22). De um modo mais amplo e ao mesmo tempo objetivo, inicia-se a partilha de uma Weltanschaung, a partir de um quadro de referência, um frame que orienta para um campo ideológico dilatado onde valores e costumes de caráter tradicionalista são alinhados a uma interpretação do pensamento liberal em termos de modelo econômico. Como já pontuado no tópico anterior, segundo a teorização mannheimiana trata-se de uma posição conscientemente assumida e refratária às circunstâncias sociais que se delineavam nos anos anteriores.

O espaço para essa partilha, especialmente para a geração mais jovem do século XXI, tem sido as redes sociais, pois esse "grupo geracional usa os espaços disponíveis, a partir da expansão da web, como estratégia de associação e espaço para comunicar posicionamentos" (Bassalo; Weller, 2015, p.250)..$^{7}$ Especialmente grupos formados por jovens se valeram dos recursos da internet para estabelecer contato, divulgar informações e fazer convocatórias alcançando uma visibilidade que não tinham anteriormente, já que as redes sociais "se tornaram o seu principal instrumento e espaço de difusão de frames, de ataque aos adversários, de convocação para as ações públicas e de acesso a novos públicos" (Silva, 2018, p.105).

O Facebook - na época e ainda sete anos depois - é a rede social mais popular entre os jovens e com maior número de usuários no Brasil e no mundo, ${ }^{8}$ de modo que em nossa pesquisa a busca por organizações juvenis com a insígnia do conservadorismo se deu nesse ambiente. Procurou-se por páginas ${ }^{9}$ que apresentassem grupos de jovens que defendem o estilo de pensamento conservador, posicionando-se entre aqueles que são reagentes às mudanças conquistadas a partir da promulgação da Constituição Federal em 1988, às políticas públicas que estavam em processo e que haviam sido propostas durante governos de caráter progressista. Vale ressaltar que para essa identificação não utilizamos nenhum usuário para acessá-las. Ou seja, a visita ao feed pode ser feita por qualquer pessoa e não requer uma conta no Facebook. Essa precaução foi tomada tendo 
em vista as recomendações quanto à ética em pesquisa em ambientes virtuais que versa sobre espaços de pesquisa, interações, a natureza dos dados no que se referem a serem considerados como públicos ou privados, avaliação de danos, anonimato e proteção (Tiidenberg, 2018; Franzke et al., 2020).

Identificou-se a criação da primeira comunidade no ano 2012, mas o período que compreende os anos 2013 a 2016 despontou como aquele com a maior concentração de lançamento de páginas, correspondendo a $63 \%$. No período posterior, após 2016, a movimentação é menor e pode-se detectar a criação de uma ou duas páginas por ano. ${ }^{10}$

A localização de páginas com a denominação conservador, associada a jovem ou estudante, gerou 24 resultados. Dessas, constatou-se que 75\%, embora estejam abertas a visita, não estão ativas, posto que não houve nenhuma postagem em 2020. Considerando o número de usuários que acompanham as páginas, $54 \%$ têm até 560 seguidores; $29 \%$, entre 1.200 e 3 mil seguidores; 8,5\% são acompanhadas por 5 a 6 mil pessoas; e, por fim, 8,5\% das páginas alcançam entre dez e 15 mil seguidores. Considerando que as contas de artistas, de digital influencers e personalidades diversas alcançam milhões de seguidores, poder-se-ia supor que esses seriam números irrelevantes. Porém, considerando que o vínculo proposto se estabelece com ideias, com um estilo de pensamento e não propriamente com uma pessoa, uma biografia, um produto com ampla aceitação ou divulgação midiática, pode-se considerar que as páginas com mais de dez mil seguidores apresentam um número significativo de pessoas interessadas nas posições que anunciam.

Ancorados em Mannheim, ou seja, no fato de que grupos concretos, nesse caso, grupos virtuais organizados em torno de uma página no Facebook, oferecem uma compreensão da unidade geracional que se autoidentifica como jovem e conservadora, bem como no Método Documentário desenvolvido por Ralf Bohnsack (2020) a partir da Sociologia do Conhecimento de Karl Mannheim, selecionamos para este estudo páginas ativas e com o mais alto número de usuários com o objetivo de analisar como grupos constituídos por jovens se apropriam do estilo de pensamento conservador e o reconfiguram na contemporaneidade.

\section{Sobre as páginas de grupos de jovens conservadores}

As páginas dos grupos no Facebook seguem a mesma estrutura, apresentam uma página inicial, um feed de notícias e acesso a álbuns de fotos e de vídeos. O item "sobre" é o local onde podem ser encontradas informações gerais registradas pelos administradores com a intenção de esclarecer ao visitante ou usuário - nem todas as páginas têm essa preocupação - sobre a natureza, missão ou compromisso da comunidade. Os administradores de uma das páginas conclamam os seguidores: "Não seja omisso, lute pelo nosso paísrs. (sic) Denuncie irregularidades e $\mathrm{f}($ sic) desse governo corrupto, estamos cansados desse desgoverno deturpando nosso país". Com essa frase os administradores identificam de modo geral uma suposta passividade como uma marca negativa de um modo 
de ser. A palavra omissão remete à falta de ação, à inércia em um momento que exige atividade. Assim, conclamam os visitantes a assumir a tarefa de denunciar o que está escuso, fora do padrão de normalidade de uma gestão pública, como os atos de corrupção.

O combate à corrupção, colocado entre os elementos que motivam os posicionamentos desse grupo que se nomeia como conservador, não tem, enquanto um elemento do discurso, uma vinculação ideológica pressuposta, posto que de acordo com Pinto (2017, p.126) "por sua popularidade em um cenário político específico, se descola da cadeia de equivalência e se torna um significado flutuante, à disposição de discursos que o disputam. A princípio, não há uma filiação ideológica nesse combate". A autora ressalva que em determinados contextos sociais, nos quais o governo é identificado como progressista ou de esquerda, "criam-se condições para que o combate à corrupção seja articulado a posições de centro-direita tornando-se equivalente a, por exemplo, Estado Mínimo, mercado e liberalismo econômico" (Pinto, 2017, p.126).

Se pensarmos que o oposto da corrupção é a honestidade e essa, por sua vez, representa um comportamento baseado num código moral que, entre outros, implica decoro, probidade e dignidade, seria impossível assegurar que em determinado governo não existisse algum tipo de fraude ou modos de aproveitamento ilícito, já que depende do julgamento particular que afeta o comportamento do indivíduo. Enquanto comportamento desonesto, a corrupção é algo que pode acontecer em qualquer governo e posicionar-se contra ela não requer um vínculo político ou ideológico específico. No entanto, os jovens tomam para si a tarefa do combate à corrupção, transformando-a em uma bandeira de atuação associada ao ser conservador. Nessa apropriação, os não conservadores passam a ser tratados por eles como corruptos ou desonestos.

Os jovens demonstram ter consciência de como querem ser identificados ao acrescentarem em sua descrição a frase: "Somos jovens conservadores e não temos vergonha disso". Parecem estar cientes de que essa opção não é comumente associada aos jovens. No entanto, ao afirmarem não terem "vergonha" de se nomearem conservadores, afirmam não existir contradição na associação da juventude com posicionamentos conservadores e, nesse aspecto, confirmam o que já foi apontado por Karl Mannheim. Bonazzi (1998) ressalta que o uso da palavra conservador como adjetivo - a exemplo da autonomeação como jovens conservadores - aponta para um conjunto de ações que pontua uma polarização, marcadamente emocional, que opõe um grupo a outro que se apresenta como inovador. A marca do ser conservador não seria em si mesma algo concreto, conceitual, já que ela se organiza na reação às proposições que podem cindir com determinado estado de coisas.

Poder-se-ia então afirmar que a característica dos conservadores de não sistematizar ideias, não teorizar acerca do conceito de conservadorismo fragilizaria sua existência. Entretanto, em contextos histórico e sociais movidos por 
processos inovadores e progressistas, unidades geracionais opositoras eclodirão na defesa da herança cultural conservadora. Sua potência reside em conectar tendências estabelecidas coletivamente em torno de conteúdos identificados por eles como nocivos ao estabelecimento de determinada ordem. Como exemplo, podemos citar a reação de grupos religiosos ao conceito de família e a criação do termo "ideologia de gênero" (MisKolci; Campana, 2017; Junqueira, 2018), que foi rapidamente absorvido como um slogan por frações da sociedade que recusam novas conformações familiares, não só no Brasil, mas também em outros países. Os jovens que se denominam conservadores, mesmo que não tenham uma definição clara do conservadorismo que, em tese, sustentaria suas ações, representam uma unidade geracional com a tarefa de estabelecer uma polarização com temas, grupos e objetos difusos que indiquem caráter inovador ou progressista e o fazem a partir de um posicionamento enquanto herdeiros culturais do conservadorismo.

Observa-se nas páginas dos grupos a reunião de elementos distintos e amplos que constituem uma pauta em defesa de uma sociedade conservadora. Cada defesa se estabelece a partir da identificação de um tema potencialmente contrário a seus interesses. Uma postura majoritária é a defesa da democracia vinculada aos princípios do liberalismo econômico, das noções de direito à propriedade privada e à liberdade da ação individual. A reação se dirige a qualquer outra lógica de ação que suponha uma atuação popular ampla, capaz de modificar leis e colocar em risco decisões do âmbito econômico. É interessante notar que, ao mesmo tempo que defendem um tipo de democracia, que inclui representatividade oriunda de um processo de escolha, também é frequente a afirmação de que são independentes, anunciando não possuírem vínculo partidário e negando uma orientação político partidária para suas ações. Defendem uma atuação voluntária, independente e de cunho comunicacional.-

Um dos elementos reunidos sob a égide da palavra conservador diz respeito à defesa da moral cristã e da família tradicional e a abjeção da reivindicação de mulheres feministas com relação à liberdade de decidir sobre o próprio corpo, especificamente em relação ao tema do aborto e das demandas de reconhecimento e cidadania dos movimentos de pessoas LGBTQI+, como o direito ao matrimônio e constituição de famílias homoparentais.

No espectro de reações é frequente a utilização de palavras ofensivas para delinear seus opositores, por exemplo, "esquerdopatas" (militante de esquerda de qualquer corrente teórica ou partido político), "petralhas" (alusão ao período em que o Partido dos Trabalhadores esteve no governo federal), "comunas", "bolsa palhaço" (referência ao programa de transferência de renda do governo petista) e "abortistas". Outro aspecto se refere a intolerância a intelectuais identificados como marxistas, a personalidades e pensadores que consideram como defensores da socialdemocracia, do socialismo ou comunismo. São assumidamente jovens que defendem um estilo de pensamento "antiprogressista" e "antiesquerda". 
Em praticamente todas as páginas o jornalista Olavo de Carvalho é apontado como referência filosófica para suas críticas e posicionamentos, absorvendo suas interpretações e, por vezes, reproduzindo neologismos irônicos ou agressivos nos debates e postagens que realizam. Supomos que essa padronização se delineie a partir do momento em que a comunicação de visões de mundo em ambientes virtuais se tornou mais efetiva e ágil com a introdução da "forma e formato difundidos por programas disponibilizados no facebook, youtube, instagram, dentre outros, que conseguem um alcance enorme se comparado à difusão dos conteúdos produzidos e difundidos pelas universidades e demais espaços científicos" (Rosa; Rezende; Martins, 2018, p.168). Desse modo, as redes sociais aumentaram a velocidade e a agilidade com que os jovens tomaram conhecimento da atividade intelectual a ponto de considerá-lo o "maior", "único", "o grande", "professor", "filósofo", dentre outros adjetivos. O acesso à sua produção se deve ao compartilhamento e fácil acesso de vídeos com palestras, entrevistas, aulas "difundidos por diferentes sujeitos e grupos que reproduzem suas visões de mundo, reiterando, portanto, certa cosmologia conservadora, cristã, colonizadora e ocidêntica encontrada nas supostas teorias acerca do que tem sido chamado de Nova Ordem Mundial, globalismo e guerras culturais" (ibidem, p.166).

Em várias páginas existem imagens de personagens e figuras que remetem às forças armadas, exaltando o período em que os militares estiveram no poder. Tal opção caracteriza uma contradição no conjunto de defesas que assumem em relação à democracia. Obviamente, nesse período os jovens usuários do Facebook não eram nascidos, portanto não experimentaram a vida, o cotidiano, do ponto de vista econômico, social, político ou cultural. Sua opção por um governo militar é, portanto, hipotética e marcadamente um recuo diante das inovações propostas em seu tempo estabelecendo-os como herdeiros culturais, herdeiros de significados, valores e interpretações de um grupo geracional que lhes antecedeu.

Outra característica comum às páginas analisadas é a defesa do governo federal, representado na figura do atual presidente, eleito em 2018, que é referenciado como "mito" e, especialmente, de dois ministérios: o Ministério da Mulher, da Família e dos Direitos Humanos, por representar a difusão de valores cristãos, e o Ministério da Educação, sobretudo pela implantação das escolas cívico-militares e ações no âmbito da Educação Superior. O apoio se manifesta por meio da replicação de posts das agências oficiais e de matérias explicativas das ações propostas ou anunciadas em cada ministério, bem como por meio da reprodução de frases proferidas pelos representantes desses órgãos.

Há ainda grupos que reagem à presença de lideranças do campo da esquerda como seus representantes estudantis nas escolas e universidades, recusando sua atuação, suas reivindicações e a trajetória de militância de outras gerações de jovens estudantes no Brasil. Defendem a reconfiguração da representação 
estudantil e a introdução do pensamento conservador nas instituições por meio de novas lideranças que devem se assumir como conservadoras. Nas chamadas das postagens que convocam para eventos de formação no âmbito acadêmico encontra-se, entre outras, a frase: "Seja um representante conservador na sua escola ou faculdade". O argumento da liberdade de pensamento, representado na frase "eu tenho direito a pensar como eu quiser" e as hashtags \#Conservador e \#ConservadoresEmMovimeto, encontra-se presente na maioria de suas postagens. Se considerarmos que a utilização de hashtag é uma maneira ágil de agrupar pessoas que falam do mesmo assunto em ambiente virtual, a inserção dessa palavra-chave em suas postagens tem o intuito de redirecionar seus usuários para outras postagens e links com o mesmo teor, ampliando, dessa forma, a quantidade de informações sobre ações no âmbito conservador e a difusão da liberdade de pensamento pregada por eles. São jovens que defendem o projeto Escola sem Partido, recusam o feminismo como teoria e prática, são críticos da União Nacional de Estudantes (UNE), são reativos ao que eles definem como "doutrinação gramscista". A intenção assumida é formar uma nova classe de digital influencers, capazes de operar como formadores de opinião em direção a uma transformação profunda no imaginário da sociedade brasileira, que realinhe símbolos e conceitos a partir de uma matriz conservadora.

\section{Considerações finais}

A partir da análise das páginas de grupos no Facebook, constata-se a existência de grupos que se definem de forma difusa como conservadores que, na perspectiva de Mannheim, constituem uma unidade geracional dentro de uma mesma conexão geracional. No entanto, parecem não reconhecer o que eles têm em comum com seus coetâneos, com aqueles que pertencem a unidades geracionais distintas e que também são jovens. Existe uma fratura entre grupos que vivem o mesmo tempo cronológico, que pertencem à mesma geração, provocada por disputas ideológicas e pela tentativa de construção de um novo contexto, no qual a apropriação do que definem como pensamento conservador passa a ser tratada como nova ou única alternativa viável para alguns grupos jovens dessa geração.

Segundo Mannheim, o agir conservador depende sempre de um conjunto concreto de circunstâncias históricas e sociais e, nesse sentido, torna-se importante refletir sobre a conjuntura que provocou a ascensão desses grupos na última década. A promulgação da Constituição de 1988, também conhecida como Constituição Cidadã pelo reconhecimento dos direitos civis e sociais, a condução política e econômica do Brasil desde meados da década de 1990, a implementação de políticas de equidade, combate às desigualdades e de proteção ao meio ambiente, entre outros aspectos, produziram modos de interpretação distintos e o agrupamento de indivíduos de acordo com posicionamentos defendidos em coletivos que foram se formando desde então. A partir dos anos 2010, movimentos que passaram a defender uma intervenção imediata, real e concreta 
fez que mais jovens passassem a se identificar com um conjunto de sentidos conservadores que estavam sendo propostos como verdadeiros e a aderir a esses grupos. No entanto, o agir concreto não se dá apenas a partir de circunstâncias históricas e sociais, mas também a partir de um chamamento e apelo individual: "Não seja omisso, lute pelo nosso país". O chamamento individual, o emprego de neologismos com teor desqualificante de seus opositores e a facilidade de mobilização nas redes sociais, constituiu um campo ideológico fértil a partir do qual a luta contra outras ideologias ou estilos de pensamento não conservadores passou a ser travada. As contradições identificadas nos grupos, por exemplo, a defesa da liberdade individual e do livre pensamento para si concomitante à negação desse direito ao outro, podem não espelhar suas orientações na esfera privada, mas, no coletivo não são questionadas, já que as intenções políticas de suas ações são bastante claras. Alinhados a outros grupos não contemporâneos à sua geração, apoiaram a destituição de uma presidente em 2016 e a eleição de um presidente que se apresenta como conservador em 2018. Também conseguiram algo inédito para seus coetâneos com a eleição de um número significativo de parlamentares jovens no Congresso Nacional e nos respectivos Estados. Contudo, não podemos afirmar que os jovens eleitos venham a se estabelecer como defensores do conservadorismo, assim como tampouco podemos afirmar que jovens não conservadores jamais mudarão de posição. Para Mannheim, "a juventude não é nem progressista nem conservadora por natureza, mas, em função de forças que estão adormecidas dentro dela, está pronta para tudo o que há de novo" (Mannheim, 1952, p.62). Como se trata de um estilo e não de um hábito de pensamento, as possibilidades de mudança são reais e uma tendência de consolidação em um ou outro espectro ou ainda a constituição de um novo estilo de pensamento, se dará com o amadurecimento da trajetória biográfica.

Por último, cabe ressaltar que, se a adesão a um grupo de dá por meio de um chamamento individual, torna-se imprescindível a realização de novos estudos, capazes de identificar como jovens elaboram seu pertencimento a um movimento conservador e como se apropriam desse estilo de pensamento. Em meados dos anos 1990, após a reunificação da Alemanha, um cientista político e estudioso de Karl Mannheim destaca a importância de nos voltarmos ao estudo dessa corrente de pensamento de uma forma que, resguardadas as diferenças entre os contextos e os respectivos tempos, também se aplica à nossa realidade: "Especialmente em tempos em que as ideologias neoconservadoras experimentam um renascimento perturbador e se misturam de forma irreconhecível com posições neoliberais ou se tornam até mesmo reacionárias, há novamente a necessidade de se lidar com essa corrente ideológica" (Hofmann, 1996, p.59).

\section{Notas}

1 Além de cientista social e autor, Paul Kecskemeti era cunhado de Mannheim e foi responsável pela tradução e edição de boa parte dos escritos de Mannheim para o 
inglês publicados na editora Routledge \& Kegan and Paul. Os originais da tese de livre-docência de Karl Mannheim encontram-se atualmente na biblioteca da Brandeis University, instituição à qual um estudante de Karl Mannheim, Kurt Heinrich Wolff, esteve vinculado (apresentação de Kettler, Meja e Stehr em Mannheim, 1984)

2 Uma versão para o espanhol dessa coletânea foi publicada em 1963 pela editora Fondo de Cultura Económica, México e Buenos Aires

3 Para maiores informações sobre o uso do conceito de constelação por Mannheim ver Garcia (1993).

4 Em outro momento Mannheim (1984, p.58) escreve: "No pensamento e na mente prevalece a liberdade; em princípio, o indivíduo pode, de forma politicamente consciente, se posicionar de forma totalmente diferente aos seus modos de pensamento. Somente nos movimentos coletivos parece que, de uma forma geral, as intenções e os estilos de pensamento estão ligados às intenções políticas".

5 O termo "posição" (Lagerung) é tomado em analogia ao conceito marxiano de posição de classe (Klassenlage). Segundo Mannheim (1964, p.528), “a posição de classe e a posição generacional (pertencimento mútuo pela proximidade dos anos de nascimento) têm em comum [...] uma forma especifica de viver e pensar, de intervir no processo histórico" que é partilhada por esses indivíduos.

6 Termo utilizado sobretudo na filosofia aristotélica que significa "a atualidade ou a perfeição resultante de uma atualização" e o "mais completo funcionamento ou culminação de uma coisa" (Mora, 2001, p.208-9).

7 Na primeira década do século XXI, os blogs tiveram importante papel como forma de comunicação via internet. Sobre pesquisa qualitativa com esse tipo de plataforma, ver: Weller, Bassalo e Pfaff (2018).

8 Informações sobre evolução, ranking das redes sociais e número de usuários podem ser obtidas no Digital 2020 April Global Statshot Report, disponível em: <https:// wearesocial.com/blog/2020/04/digital-around-the-world-in-april-2020>

9 O Facebook informa na Central de Ajuda que oferece três possibilidade de uso da plataforma: perfil, página e grupo. O perfil é destinado a pessoas individualmente, as páginas são destinadas a pessoas jurídicas, figuras públicas, comunidades e organizações e, os grupos são espaços privados de encontro. Nas páginas os administradores não são identificados, podem ter quantidade ilimitada de seguidores e todo o conteúdo é assinado com o nome da página. Nos grupos os administradores são identificados pelo nome de usuário e geralmente é necessário, convite ou inscrição e aprovação por um dos administradores. Logo, os grupos são mais restritos que as páginas e estas são, em geral, públicas podendo ser visitadas, curtidas ou seguidas por outros usuários.

10 Devemos lembrar também que outras plataformas a partir da década de 2010 começaram a dividir a atenção dos usuários de redes sociais como o crescimento do número de usuários no twitter, instagram, youtube e o aplicativo de mensagens instantâneas whatsapp. Não podemos afirmar, mas supomos que a atuação no mundo virtual seja multiplataforma, ou seja, os jovens passam a utilizar várias ao mesmo tempo ou ainda abandonam a que utilizavam inicialmente para se concentrar em outra mais recente. O whatsapp, por exemplo, foi utilizado fortemente por grupos políticos em grupos fechados após o impeachment de Dilma Rousseff e durante as eleições presidenciais de 2018, favorecendo o acesso de informações e conteúdo exclusivos aos participantes do grupo. 


\section{Referências}

BARBOSA, A. Kunst und Wissen: Die Stilanalyse in der Soziologie Karl Mannheims. UVK, 2005.

BASSALO, L. M. B.; WELLER, W. Jovem e mulher: um estudo sobre os posicionamentos de internautas feministas. In: SOUSA, C. A. M. (Org.) Juventude e tecnologias: sociabilidades e aprendizagens. Brasília: Liber Livro, 2015. p.235-54.

BOHNSACK, R. Praxiologische Wissenssoziologie. Opladen; Toronto: Barbara Budrich, 2017.

Pesquisa social reconstrutiva: introdução aos métodos qualitativos. Petrópolis: Vozes, 2020.

BONAZZI, T. Conservadorismo. In: BOBBIO, N.; MATTEUCCI, N.; PASQUINO, G. Dicionário de Política. Brasília: Editora UnB, 1998. v.1, p.242-6.

CORROCHANO, M. C.; DOWBOR, M.; JARDIM, F. A. A. Juventude e participação política no Brasil do século XXI: quais horizontes? Laplage em Revista, São Carlos, v.4, n.1, p.50-66, 2018.

FRANZKE, A. S. et al. Internet Research: Ethical Guidelines 3.0. Association of Internet Researchers. 2020. Disponível em: <https://aoir.org/reports/ethics3.pdf>. Acesso em: 7 abr. 2020.

GARCÍA, J. M. G. Reflexiones sobre "El pensamiento conservador" de Karl Mannheim. Madrid: Reis, 1993. p.61-81.

HOFMANN, W. Karl Mannheim zur Einführung. Hamburg: Junius, 1996.

JUNQUEIRA, R. D. A invenção da "ideologia de gênero": a emergência de um cenário político-discursivo e a elaboração de uma retórica reacionária antigênero. Revista Psicologia Política. v.18, n.43, p.449-502, 2018.

KNOBLAUCH, H. Wissenssoziologie. Konstanz: UVK, 2005.

MANNHEIM, K. Diagnose unserer Zeit. Gedanken eines Soziologen. Frankfurt/M.: Büchergilde Gutenberg, 1952.

Das Problem der Generationen. In:

Wolff. Neuwied: Luchterhand, 1964. p.509-65. Wissenssoziologie. Introd. e ed. K. H. Conservative Thought. In: From Karl Mannbeim. Introd. e ed. K. H. Wolff. New York: Oxford University Press, 1971. p.132-222.

. Structures of Thinking. London; New York: Routledge \& Kegan Paul, 1982.

. Konservatismus. Ein Beitrag zur Soziologie des Wissens. Introd. e ed. D. Kettler; V. Meja; N. Stehr. Frankfurt/M: Shurkamp, 1984.

El problema de las generaciones. REIS - Revista Española de Investigaciones Sociológicas, Madrid, n.62, p.193-242, abr./jun. 1993.

MISKOLCI, R.; CAMPANA, M. "Ideologia de gênero": notas para a genealogia de um pânico moral contemporâneo. Sociedade e Estado, Brasília, v.32, n.3, p.725-48, dez. 2017.

MORA, J. F. Dicionário de Filosofia. São Paulo: Martins Fontes, 2001.

PINTO, C. R. J. A trajetória discursiva das manifestações de rua no Brasil (2013-2015).

Lua Nova, São Paulo, n.100, p.119-53, 2017. 
ROCHA, C. "Imposto é Roubo!" A Formação de um Contrapúblico ultraliberal e os Protestos Pró-Impeachment de Dilma Rousseff. Dados, Rio de Janeiro, v.62, n.3, e20190076, 2019.

ROSA, P. O.; REZENDE, R. A.; MARTINS, V. M. V. As consequências do etnocentrismo de Olavo de Carvalho na produção discursiva das novíssimas direitas conservadoras brasileiras. Revista NEP, Curitiba, v.4, n.2, p.164-246, dez. 2018.

SCHÄFFER, B. Generationen - Medien - Bildung: Medienpraxiskulturen im Generationenvergleich. Opladen: Leske + Budrich. 2003

SILVA, M. K. A apropriação conservadora do ciclo de protestos de 2013: rumo aos protestos anti-Dilma? Lusotopie, v.17, n.1, p.88-111, 2018.

TIIDENBERG, K. Ethics in Digital Research. In: FLICK, Uwe. (Ed.) The SAGE Handbook of Qualitative Data Collection. London: Sage, 2018. p.466-79.

WELLER, W. A atualidade do conceito de gerações de Karl Mannheim. Sociedade e Estado, v.25, n.2, p.205-24, 2010.

WELLER, W.; BASSALO, L. M. B.; PFAFF, N. Collecting data for Analyzing Blogs. In: FLICK, Uwe. (Org.) The SAGE handbook of Qualitative Data Collection. London: SAGE, 2018. p.482-95.

RESUMO - Com base nos escritos de Karl Mannheim sobre os estilos de pensamento na primeira metade do século XIX e de como esses constituem-se em unidades geracionais dentro de uma mesma conexão geracional, o artigo se volta ao estudo de grupos de jovens conservadores no Facebook. O propósito é compreender como grupos de jovens anunciam publicamente e em ambiente virtual uma herança cultural relacionada a um estilo de pensamento conservador. A análise dos posicionamentos dos jovens conservadores internautas revela uma apropriação difusa do conceito de conservadorismo, mas estratégias claras de polarização com outros grupos e estilos de pensamento. Enquanto herdeiros culturais do conservadorismo, assumem para si a tarefa de transformar a sociedade brasileira em direção a uma matriz conservadora.

PALAVRAS-Chave: Juventude, Gerações, Pensamento conservador, Conservadorismo, Karl Mannheim.

ABSTRACT -Based on Karl Mannheim's writings on different styles of thoughts in the first half of the 19th century and on how they constitute generational units within the same generational connection, this article focuses on the study of conservative youth groups on Facebook. The purpose is to understand why groups of young people publicly announce, in a virtual environment, a cultural heritage related to a conservative way of thinking. The analysis of conservative youth groups on the internet unveils a diffuse appropriation of the concept of conservatism, but also clear strategies of polarization vis-à-vis other groups and styles of thinking. Seeing themselves as cultural heirs of conservatism, they take on what they perceive to be a responsibility of transforming Brazilian society towards a conservative matrix.

KEYWORDS: Youth, Generations, Conservative thought, Conservatism, Karl Mannheim. 
Wivian Weller é doutora em Sociologia pela Freie Universität Berlin, professora do Programa de Pós-Graduação em Educação da Universidade de Brasília (UnB) e bolsista produtividade em pesquisa do CNPq - PQ1C. @- wivian@unb.br / https://orcid.org/0000-0003-1450-2004.

Lucélia de Moraes Braga Bassalo é doutora em Educação pela Universidade de Brasília (UnB) e professora do Programa de Pós-Graduação em Educação da Universidade do Estado do Pará (UEPA). @- lbassalo@uol.com.br /

https://orcid.org/0000-0002-0412-6052.

Recebido em 12.5.2020 e aceito em 14.6.2020.

${ }^{\text {I }}$ Faculdade de Educação, Universidade de Brasília, Brasília, Brasil.

${ }^{\text {II }}$ Departamento de Filosofia e Ciências Sociais, Universidade do Estado do Pará, Belém, Brasil. 
